\title{
The Application Study of the Advanced Power Electronics in the Smart Grid
}

\author{
WANG Yixi ${ }^{1, a}$, XU Jingjin ${ }^{2, b}, X U$ Huan ${ }^{3, c}$, LONG Fei ${ }^{4, d}$ \\ 1,2,3,4National network Hubei Electric Power Co., Ltd. information and communication \\ company, Wuhan, Hubei 430077 China \\ a187355144@qq.com, b xujingjin@hb.sgcc.com.cn, c53287272@qq.com , \\ d469277158@qq.com
}

Keywords: Advanced power electronics; smart grid; application study

\begin{abstract}
With the constant social development, smart grid develops towards digitization, automation and information in the electric system. In the smart grid, the application of power electronics has the extremely important significance and can greatly improve operation safety and operation efficiency of smart grid. In this paper, the author firstly analyzed the demands of smart grid development for power electronics and then studied the application of power electronics in the smart grid.
\end{abstract}

\section{Introduction}

The development in today's society tends to energy saving and environmental protection. In power system development, structure, technology and scale gradually become improved and perfect. Driven by the economic development, it receives impact to some extent, thus power system still has some problems in energy saving and emission reduction. It should be further analyzed and explored, so as to promote the development and progress of smart grid.

\section{Unified Power Flow Controller (UPFC)}

With the development of the power system, power network becomes increasingly complicated. The operation also becomes more complicated and changeable. The requirements for the power system safety and economy are also improving, thus this brings some new challenge to the power system development, especially for the stability of the power system. The UPFC is composed of a transformer that is connected to the transmission network in parallel, a transformer that is connected to the transmission grid in series, two converters and a controller. UPFC is installed on one end of nodes for controlling flow in power grid. By analyzing the above-mentioned UPFC working principle, we can obtain the equivalent circuit model for further studying the control of the power system.

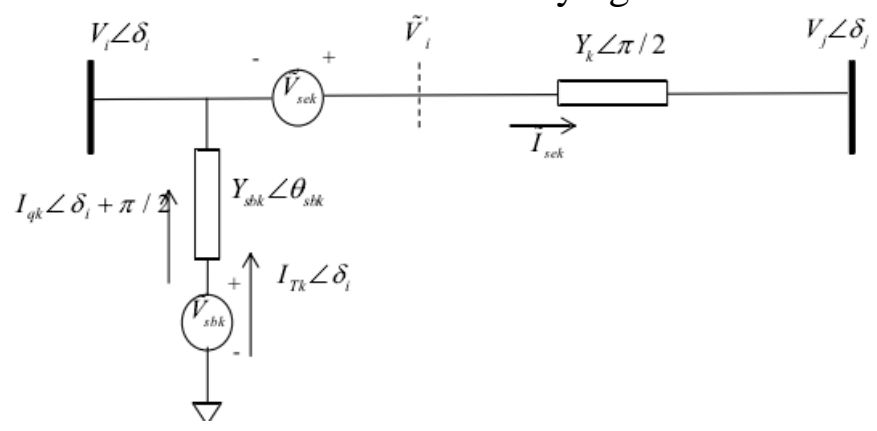

Fig.1 The Equivalent Circuit of UPFC

In the equivalent circuit, the equivalent node voltage is the sum between the original node voltage and injecting voltage, namely $\tilde{V}_{i}=\tilde{V}_{s e k}+\tilde{V}_{i}$. The equivalent voltage source in series of UPFC $\tilde{V}_{\text {sek }}$ can be controllable in the amplitude and phase angle. THe mathematical expression is shown as: 


$$
\tilde{V}_{\text {sek }}=r_{k} \tilde{V}_{i} e^{j \alpha_{k}}
$$

With the restraint of enlargement factor inequation $0 \leq \mathrm{rk} \leq \mathrm{rkmax}$, the phase angle should meet $0 \leq \mathrm{ak} \leq 2$, thus the equivalent current of UPFC injecting to the line is:

$$
\begin{aligned}
& \tilde{I}_{s e k}=Y_{i j} e^{j \pi / 2}\left(V_{i} e^{j \delta_{i}}+r_{k} V_{i} e^{j \gamma_{k}}-V_{j} e^{j \delta_{j}}\right)-Y_{i j} e^{j \pi / 2}\left(V_{i} e^{j \delta_{i}}-V_{j} e^{j \delta_{j}}\right) \\
= & r_{k} Y_{k} e^{j\left(\pi / 2+\gamma_{k}\right)} V_{i}
\end{aligned}
$$

Where $\gamma_{k}=\delta_{i}+\alpha_{k}$; UPFC is injected into the active power and inactive power of node $\mathrm{i}$ and node $\mathrm{j}$, as

$$
\begin{aligned}
& P_{u p f \in \_, k}^{i}=r e\left[\tilde{V}_{i}\left(-\tilde{I}_{s e k}^{*}\right)\right]+V_{i} I_{T k}=-r_{k} V_{i}^{2} Y_{k} \sin \left(\delta_{i}-\gamma_{k}\right)+V_{i} I_{T k} \\
& Q_{\text {qpf } c_{-\mathrm{k}}}^{i}=i m\left[\tilde{V}_{i}\left(-\tilde{I}_{s e k}^{*}\right)\right]+V_{i} I_{q k}=r_{k} V_{i}^{2} Y_{k} \cos \left(\delta_{i}-\gamma_{k}\right)+V_{i} I_{q \mathrm{k}} \\
& P_{u p p \in \_ \text {_ }}^{j}=\operatorname{re}\left(\tilde{V}_{j} \tilde{I}_{s e k}^{*}\right)=r_{k} V_{i} V_{j} Y_{k} \sin \left(\delta_{j}-\gamma_{k}\right) \\
& Q_{\text {pqf } \_ \text {k }}^{j}=\operatorname{re}\left(\tilde{V}_{j} \tilde{I}_{s e k}^{*}\right)=-r_{k} V_{i} V_{j} Y_{k} \cos \left(\delta_{j}-\gamma_{k}\right)
\end{aligned}
$$

The author introduced the structure of smart grid and transient state protection system, elaborated the mathematical model of the transient power grid, and introduced the UPFC for controlling power grid network.

\section{The Application of DC Transmission Technology in the Smart Grid}

The Application of the Conventional HVDC Technology in the Smart Grid. HVDC has advantages in high-capacity transmission, asynchronous networking and submarine cable power transmission in the remote distance, thus it is widely applied. EHVDC can effectively save power transmission corridors, reduce system losses and improve power transmission economy. It provides the effective approach to solve uneven energy distribution and optimize resource allocation. It is predicted that in 2020, China will construct the "strong AC and DC" EHV mixed power grid, strong delivery and receiving client power grid. It is predicted the DC projects will be up to 50, including more than $30 \mathrm{EHV}$ projects, which have $5 \pm 1000 \mathrm{KV}$ DC projects. Moreover, $\pm 660 \mathrm{KV}$ Ningdong-Shandong DC project was launched. The single valve's withstand voltage level was the top one in the transmission project, while the single valve's cascade thyristor quantity was also the top in all projects. Also, the feasibility of $1000 \mathrm{kV} / 5 \mathrm{kA}$ EHVDC projects is also studying. EHVDC above $\pm 800 \mathrm{kV}$ applies double 12-impulse converter valve for the converter valve. Shown in Figure 1 , 500 and $660 \mathrm{KV}$ projects apply single 12 -impulse converter valves. In the future, Chinese DC system will form 125,500, 660, 800, $1000 \mathrm{KV}$ voltage class sequence and form the rated current of 3, 3.5, 4,4.5, 5KA of current grade sequences.

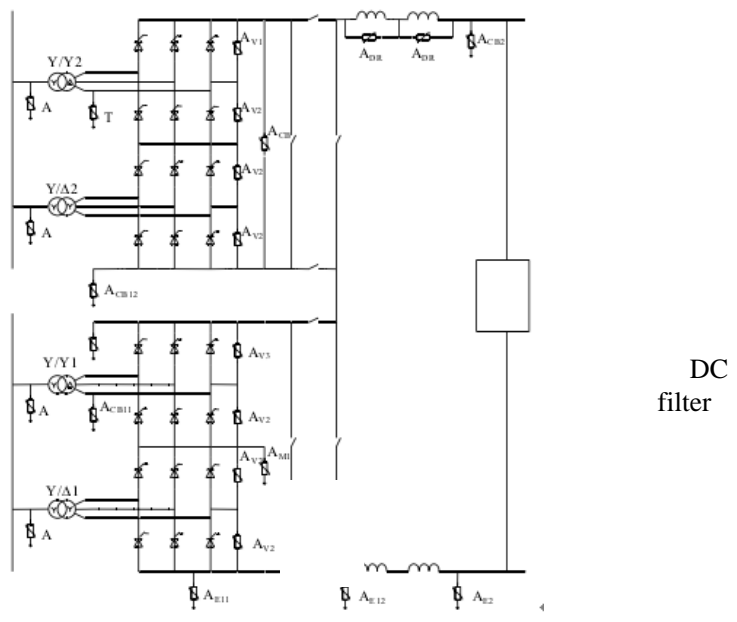

Fig.2 Basic Line Connection for EHVDC Convertor Station 
Application of Flexible DC Technology in Smart Grid. The converter of the flexible DC transmission system applies the self-commutation, showing four-quadrant operation and independent control of active and inactive power. It is good for constituting in the multi-end DC transmission system that is convenient for controlling flow and has the higher reliability. When it is used for networking, it won't increase the short-circuit capacity of the system. Each converter station can independently control. There is no need for communication between convertor stations. These unique technical advantages make it develop a positive role on the distributed generation connection, isolated load, power supply in remote areas, and urban power grid connection.

In recent years, Chinese power demands and installation growth are extremely rapid, so the networking demands of power grid in each area are increasingly growing. The networking in power grid lies in mutual aid of electric energy and support of dynamic active power, but it also will reduce dynamic stability for power grid and overproof of short-circuit current. Dynamic stability is a widespread problem in each large power grid of China. It is the bottleneck for safety and stability of power system, while the overshoof of short-circuit current is increasing with the urban load and it has already become a special problem in the large-scale urban power grid. The flexible DC transmission system has the special advantages to solve regional power grid, weak interconnection of power system and nonsynchronous interconnection of power system in surroundings. This can solve various problems faced by the regional interconnection to a large extent. It conforms to the developmental requirements of smart grid. International studies on the flexible DC transmission have been profound in engineering functionization or basic theories. ABB company has already operated 9 flexible DC transmission projects, which have been operating normally and have acquired the excellent benefits. Main technical parameters of VSC-HVDC converter were shown in Table 1.

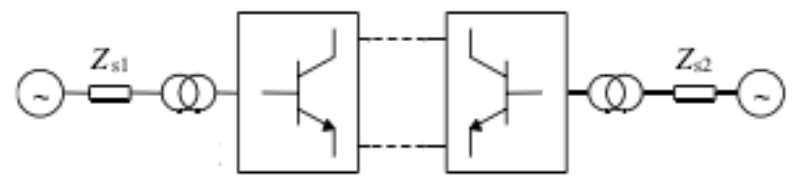

Fig.3 The Electrical Main Wiring Diagram of the Flexible DC Demonstration Project Tab.1 Main Technical Parameters of the Flexible DC Converter

\begin{tabular}{|c|c|c|c|c|c|c|}
\hline $\begin{array}{c}\text { Transfo } \\
\text { rmer } \\
\text { substati } \\
\text { on }\end{array}$ & $\begin{array}{c}\text { Topology of } \\
\text { the } \\
\text { converter }\end{array}$ & $\begin{array}{c}\text { AC System } \\
\text { Voltage/KV }\end{array}$ & $\begin{array}{c}\text { AC System } \\
\text { Nominal } \\
\text { Frequency/ } \\
\text { Hz }\end{array}$ & $\begin{array}{c}\text { DC Rated } \\
\text { Voltage/KV }\end{array}$ & $\begin{array}{c}\text { Rated } \\
\text { Capacity }\end{array}$ & Rated DC/A \\
\hline $\begin{array}{c}\text { Nan } \\
\text { hui }\end{array}$ & $\begin{array}{c}\text { Modular } \\
\text { multiple } \\
\text { levels VSC }\end{array}$ & 35 & 50 & \pm 30 & $\begin{array}{c}20 \mathrm{MVA} / \\
18 \\
\text { MW }\end{array}$ & 300 \\
\hline $\begin{array}{c}\text { Daz } \\
\text { hi }\end{array}$ & $\begin{array}{c}\text { Modular } \\
\text { multiple } \\
\text { levels VSC }\end{array}$ & 35 & 50 & \pm 30 & $\begin{array}{c}20 \mathrm{MVA} / \\
18\end{array}$ & 300 \\
\hline
\end{tabular}

\section{Application of Advanced Power Electronics in the Smart Grid}

The Application in the Smart Grid Power Generation. How to realize sustainable utilization of energy in the society with rapid development is the new challenge. In smart grid, the advanced power electronics can relieve pressure brought by nervous energy to save energy and protect environment. In the power generation of smart grid, the application on the advanced power electronics is mainly reflected in the advanced technology and uses wind energy and water energy for power generation. For example, as using wind energy to generate power, the electronics in the generator system uses the advanced technology in the grid to realize the variable speed operation, control charge and discharge process of batteries, and ensure stable power supply. 


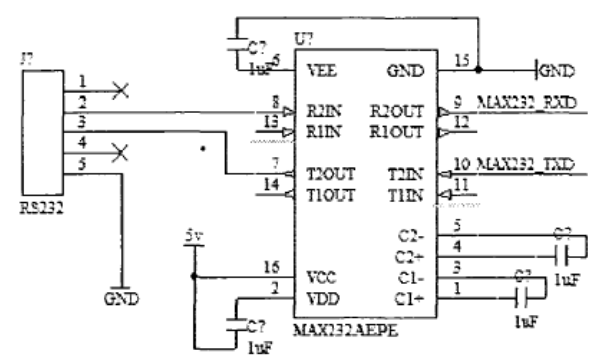

Fig.4 Communication Module Circuit Design

Application of Wind Energy, Photoelectrical Energy and Storage Mixture. Wind energy and photoelectrical energy are clean renewable energy sources and they are increasingly important in the green application. They are considered as the development tendency in the future resources and meet lots of social demands. however, there are unstable factors in wind energy and photoelectrical energy. As a result, in practical application, it is necessary to notice the relation between production powers and loads. In the actual application, the large power convertor should be used to connect with the power system, realize energy conversion and ensure the perfect connection of large power voltage sources and storage equipment in the power system. In this way, this not only can realize lots of storage for energy, but also greatly improve quality of power resources.

Application of Smart Grid Transmission. There are lots of technical parameters in power transmission of energy, including DCHV transmission and flexible DC transmission. The advanced power electronics can ensure transmission stability for DC transmission. The combination of the advanced power electronics and power system can control the power system in line with the physical truth. The perfect combination of electronics and control technology can commonly regulate smart grid, so as to greatly enhance stability of smart grid and guarantee power quality of transmission.

Application in Smart Grid Power Transmission. In recent years, the substation develops towards the digitalization direction from the traditional mode. This relies on constant revolution of power electronics. In the future, the developmental tendency of the substation realizes information sharing and mutual application through the larger exchange platform. On the basis of the digitalization in the substation, innovation is constantly realizing to realize the intelligence and informatization of the substation grid. As a result, the future intelligent grid not only is the digital collection and display, but completes the digital analytical functions through the advanced power electronics. The photoelectric technology, replacement of traditional relay by programming procedures and microprocessor can be used to realize the logical function module.

Application in the Smart Grid Power Generation. At present, the competition in the power system market mainly realizes mutual interaction between users. This the primary target of power generation in the smart grid. In this process, advanced power electronics can be used to complete information requirements for power suppliers and power users, so as to ensure users' actual demands for power. The smart devices used in this process include the smart protectors, automatic equipment, smart labeling, and data processing equipment, so as to realize the high-speed data transmission between power suppliers and users.

Application in the Smart Grid Power Distribution. In the power transmission of smart grid, it must ensure users' quality demands for power. In the power distribution process, if there are problems, it must be solved in time. moreover, information collected by the sensing measurement technology can be integrated through the network, so as to further coordinate control and improve power quality in the power distribution process.

\section{Conclusions}

Electronic power transformers have the excellent proprieties to solve lots of problems in the modern electric system. In this paper, the author studied the PV power generation system by using power electronic transformers connecting to the power grid as the topic, mainly studied basic output properties of PV system, and realized the transient state and stable properties through the power electronic transformers. 


\section{References}

[1] Xing Ao, the Application of Electronic Technique in the Power System[J], Electronic Technique and Software Engineering, 2017, 20: 230-231;

[2] Huang Huajuan, the Application Study of Power Electronics in Power System[J], Shandong Industrial Technology, 2017, 11:211;

[3] Song Binbin, Wang Huiduo and Zhang Ting, the Application Study of the Advanced Power Electronics[J], Electronic Technique and Software Engineering, 2015, 21: 243;

[4] Ren Jian, the Application Analysis of the Advanced Power Electronics in the Smart Grid[J], Communication World, 2016, 06: 128;

[5] Yin Xiaofeng, the Application of the Advanced Power Electronics in the Smart Grid[J]. Electronic World, 2016, 09: 118 